\title{
USO DE ÁREAS VERDES EM MOGI MIRIM: PREFERÊNCIA DA POPULAÇÃO
}

\author{
Valeska Ribeiro Marques ${ }^{1}$, Luiz Felipe Silva², Gleise Regina Bertolazi dos Santos ${ }^{3}$ \\ Nancy Laura Rios Gamarra ${ }^{4}$
}

\section{RESUMO}

As áreas verdes melhoram a qualidade de vida da população, podem diminuir extremos de temperatura, atenuar ruído, reter poeira, aumentar a área permeável urbana, oferecer um espaço agradável para prática de atividade física e o convívio social, entre outros inúmeros benefícios. Trata-se de um espaço que se comporta como um promotor de saúde da população. O objetivo deste trabalho foi levantar quais áreas verdes são utilizadas na cidade de Mogi Mirim, estado de São Paulo. A metodologia utilizada foi uma investigação epidemiológica observacional com característica de um estudo transversal de base populacional. Foram entrevistados, por amostragem aleatória, 262 pessoas. Dos entrevistados, $47 \%$ frequentam as áreas verdes, no mínimo uma vez por semana, para o convívio social $(30,2 \%)$, atividade física $(29,4 \%)$, lazer com crianças $(21,8 \%)$ e passear com cão $(9,2 \%)$. As praças são as áreas mais procuradas. Destaca-se o Complexo Lavapés, frequentado por $23 \%$ dos entrevistados, dos quais $90 \%$ residem a até três quilômetros da área verde. Este estudo é um recurso relevante, pouco encontrado na literatura científica nacional, na medida em que procura estudar as relações entre área verde e saúde e assim contribuir para a adoção destes locais, como prática essencial de promoção à saúde.

Palavras-chave: Estudo de base populacional; Promoção da saúde; Distância entre residência e área verde. 


\section{USE OF GREEN SPACES IN MOGI MIRIM: POPULATION PREFERENCE}

\section{ABSTRACT}

Green areas improve the quality of life, can reduce temperature extremes, mitigate noise, dust retaining, increasing permeable urban area, offering a pleasant space for physical activity and social interaction, among many other benefits. This is a space that behaves as a promoter of health of the population. The objective of this study was to identify which green areas are used in the city of "Mogi Mirim, São Paulo". The methodology used was an observational epidemiological investigation with the feature of a cross-sectional populationbased study. They were interviewed by random sampling, 262 people. Of the respondents, $47 \%$ use the green areas at least once a week, for social life $(30.2 \%)$, physical activity (29.4\%), leisure with children (21.8\%) and walk with dog (9.2\%). The municipal squares are the most popular areas. Noteworthyis the "Complexo Lavapés", attended by $23 \%$ of respondents, of which $90 \%$ live up to three kilometers of green aera. This study is relevant, little found in the national literature, in that it seeks to study the relationship between green space and health and thus contribute to the adoption of these local settings as an essential practice of health promotion.

Keywords: Population-based study; Health promotion; Distance between residence and green area.

\section{INTRODUÇÃO}

Erro! Indicador não definido.

Áreas verdes são primordiais no contexto urbano e estão associadas à qualidade de vida da população. Frequentar as áreas verdes pode trazer diversos benefícios à saúde e ao bem estar das pessoas. No Brasil $84,35 \%$ da população vivem em cidades (IBGE, 2010).

Diversos países vêm pesquisando os efeitos positivos da utilização das áreas verdes. O reflexo destes estudos é a inclusão, no planejamento político, da melhoria e do aumento das áreas verdes urbanas (SCHIPPERIJN et al., 2010). No contexto internacional é possível observar uma preocupação em ampliar o uso destes espaços, fazendo com que sejam cada vez mais frequentados. Investir em áreas verdes pode significar uma grande 
economia nos gastos com a saúde, pois estes espaços podem contribuir na redução do nível de estresse, cada vez maior no ambiente urbano, favorecendo o convívio social e a prática de esportes (GRAHN; STIGSDOTTER, 2003).

Diversos fatores estão associados ao uso das áreas verdes, como: idade, escolaridade, nível social, saúde, distância da residência, ter filhos pequenos, entre outros. As áreas verdes são percebidas pelos indivíduos de diferentes maneiras e a compreensão do que é oferecido está associada também a aspectos culturais (KESSEL et al., 2009). Pistas de corrida e ciclovias podem incentivar o uso do espaço por um determinado grupo de pessoas e desestimular outros. Portanto, o que é oferecido pelo espaço determinará sua utilização ou não de acordo com o perfil da comunidade local. Entendendo melhor a motivação para o uso das áreas verdes é possível realizar planejamento e manutenção destes espaços de acordo com as necessidades reais da população.

Existem ainda os benefícios ambientais oferecidos pelas áreas verdes, relacionados diretamente à saúde da população urbana. Estes benefícios dependem do tamanho e das características do espaço verde, mas de modo geral são: diminuição de ruídos, retenção de poeira, aumento da área permeável urbana, diminuição da temperatura, ambientação de pássaros e beleza são alguns fatores que influenciam positivamente a saúde da população urbana. Portanto, mesmo indivíduos que não frequentam estes espaços são favorecidos, pois os benefícios ambientais não se restringem aos limites da área (MARQUES, 2013).

É necessário compreender como a população percebe o ambiente a sua volta, e quais valores são conferidos às áreas verdes, para entender melhor a motivação que leva a população a utilizar tais espaços. Por tanto, o objetivo deste trabalho foi determinar quais áreas verdes são utilizadas pela população na cidade de Mogi Mirim - SP. Para assim, contribuir com o desenvolvimento de políticas públicas e assegurar um ambiente adequado às características da população local.

\section{MATERIAIS E MÉTODOS}

O município de Mogi Mirim está localizado na região nordeste do estado de São Paulo, latitude $22,43^{\circ}$ sul e longitude $46,95^{\circ}$ oeste. Possui área de 497,78 km², 86.505 habitantes e densidade demográfica de 173,78 hab./ km² (IBGE, 2010).

De acordo com a Secretaria de Obras e Planejamento de Mogi Mirim, o município possui 117 áreas verdes cadastradas, incluindo praças, praças de condomínio fechado, rotatórias e áreas sem uso. Nesta pesquisa, foram identificadas, com apoio dos profissionais 
da Casa da Agricultura, 67 praças com estrutura mínima de uso para população (calçada e arborização), e assim cumprindo minimamente as funções ecológicas, estéticas e de lazer, conforme definição de Matias e Caporusso (2009). Foram utilizadas, como ferramentas, para identificação das praças aptas ao uso da população, o programa de computador Google Earth (2012) e o mapa impresso do município de 2010.

A metodologia utilizada foi uma investigação epidemiológica observacional, pela qual, questionários foram aplicados para obter dados sociodemográgicos e comportamentais. Foi conduzido um estudo transversal de base populacional para se obter a frequência de ocorrência de um evento (frequentar área verde), numa população (Mogi Mirim), em um ponto no tempo, ou curto espaço de tempo (KELSEY et al., 1986).

Foi determinada uma amostra de base populacional, fundamentada no trabalho de Gil (1995). Pelo método, considerando populações finitas, tendo como referência o número inferior a 100.000 observações, desse modo, para o cálculo da amostra, empregou-se a Equação 1:

$$
n=\frac{\delta^{2} \cdot p \cdot q \cdot N}{e^{2}(N-1)+\delta^{2} \cdot p \cdot q}
$$

Em que:

$\mathrm{n}$ = tamanho da amostra: número de entrevistas a serem realizadas;

$\delta^{2}=$ estimativa do nível de confiança determinado, expresso em números de desvio-padrão;

$\mathrm{p}=$ probabilidade de ocorrência do fenômeno, frequentar área verde;

$\mathrm{q}=1-\mathrm{p}$; probabilidade de fracasso;

$\mathrm{N}$ = dimensão da população, número de habitantes;

e = erro máximo permitido.

Para a definição da amostra, foram adotados dois erros-padrão, valor de $p=0,5 \mathrm{e}$ consequentemente, $q=0,5$; e o erro máximo permitido de $6 \%$, conforme Richardson (2008) e pesquisa conduzida por Machado et al. (2014). A população de Mogi-Mirim, segundo o censo de 2010, era de 86.505 habitantes (IBGE, 2010). Desse modo, com a aplicação da Equação 1 tem-se um valor de $\mathrm{n}$ igual a 277 indivíduos participantes.

Foram definidos 318 domicílios, considerando a definição de uma margem de segurança de $10 \%$ em relação à dimensão da amostra calculada, e adicionando $5 \%$ para eventuais recusas ou perdas. Este valor foi distribuído aleatoriamente e proporcionalmente 
entre os mapas dos setores censitários do município de Mogi Mirim. O estudo se concentrou na zona urbana, por amostragem aleatória organizada em conglomerados. Os domicílios permanentemente desocupados e os domicílios encontrados fechados foram substituídos pelos imediatamente subsequentes, obedecendo aos mapas setorizados do IBGE.

A amostragem foi extraída por um processo aleatório aplicando o programa Excel 2010 para realização de sorteio e determinação das residências que participariam da pesquisa, utilizando os mapas censitários do IBGE.

Considerando os aspectos éticos, o estudo foi aprovado pelo Comitê de Ética em Pesquisa, no mês de novembro de 2011, sob o parecer de número 744/2011, conforme Resolução 196/96 do Conselho Nacional de Saúde.

As entrevistas foram iniciadas em fevereiro 2012 e finalizadas em agosto do mesmo ano. Em cada domicílio selecionado foi entrevistado um morador adulto (com 18 anos de idade ou mais), que após explicação sobre o objetivo da pesquisa os entrevistados assinaram voluntariamente o Termo de Consentimento Livre e Esclarecido, para realização da aplicação do questionário padronizado. O questionário abordou tópicos acerca da percepção sobre saúde, hábitos, características pessoais e outras variáveis possivelmente associadas à frequência de uso de áreas verdes. Os questionários respondidos pelos indivíduos que residem há menos de dois anos em Mogi Mirim foram descartados para evitar influência da pouca adaptação e não conhecimento das opções de áreas verdes do município. As análises foram realizadas com auxílio do Epi-info versão 3.5 .2 (2010).

Para o cálculo da distância da área verde mais frequentada (Complexo Lavapés) foi utilizado o programa ArcGIS 10.0 partindo das coordenadas do Complexo Lavapés à residência do entrevistado mediante a função Near analysis. Os valores da distância foram separados em intervalos de 500 metros.

Com o fim de oferecer uma compreensão mais adequada da população estudada, uma análise descritiva foi conduzida para os dados amostrais. Foi aplicado, no nível de 95\% de confiança, o teste t de student para verificar as diferenças entre as variáveis quantitativas e o teste de qui-quadrado para analisar a significância das diferenças entre as variáveis categóricas.

\section{RESULTADOS E DISCUSSÃO}

Dos 262 entrevistados, com relação à variável idade, houve predominância na faixa etária dos 38 aos 57 anos, com 47,7\% da amostra pertencente a esse grupo. A média de 
idade da amostra foi de 44,7 anos ( $\underline{\sigma}= \pm 15,7$ ) para as mulheres e 48,1 anos ( $\underline{\sigma}= \pm 15,7$ ) para os homens. Como valores máximos, foi entrevistada uma mulher com 88 anos e um homem com 85 anos. Com relação à escolaridade, observa-se que 19,5\% da amostra atingiram o nível superior. A prevalência de conclusão do ensino médio foi de $46,2 \%$.

A Tabela 1 contém características da amostra, segundo as principais variáveis contidas no questionário, por gênero. Não foi encontrada diferença significativa entre as proporções de respondentes entre homens (47\%) e mulheres (53\%).

Tabela 1. Características da amostra entrevistada segundo as variáveis do questionário, por gênero

Table 1. Characteristics of the study sample according to the questionnaire variables, by gender

\begin{tabular}{|c|c|c|c|c|c|c|}
\hline \multirow{2}{*}{ Variáveis } & \multicolumn{4}{|c|}{ Gênero } & \multirow{2}{*}{\multicolumn{2}{|c|}{ Total }} \\
\hline & \multicolumn{2}{|c|}{ Masculino } & \multicolumn{2}{|c|}{ Feminino } & & \\
\hline 18 a 37 & 35 & $28,5 \%$ & 45 & $32,4 \%$ & 80 & $30,5 \%$ \\
\hline 38 a 57 & 57 & $46,4 \%$ & 68 & $48,9 \%$ & 125 & $47,6 \%$ \\
\hline 58 e mais & 31 & $25,2 \%$ & 26 & $18,7 \%$ & 57 & $21,9 \%$ \\
\hline \multicolumn{7}{|l|}{ Escolaridade } \\
\hline Fundamental & 44 & $35,8 \%$ & 46 & $33,1 \%$ & 90 & $34,4 \%$ \\
\hline Médio & 53 & $43,1 \%$ & 68 & $48,9 \%$ & 121 & $46,2 \%$ \\
\hline Superior & 26 & $21,1 \%$ & 25 & $18,0 \%$ & 51 & $19,5 \%$ \\
\hline Ter filho de até 10 anos & 35 & $28,5 \%$ & 31 & $22,3 \%$ & 66 & $25,2 \%$ \\
\hline Posse de cão & 74 & $60,2 \%$ & 79 & $56,8 \%$ & 153 & $58,4 \%$ \\
\hline Fumante & 32 & $26,0 \%$ & 18 & $12,9 \%$ & 50 & $19,1 \%$ \\
\hline Usa medicamento hipertensão & 29 & $23,6 \%$ & 29 & $20,9 \%$ & 58 & $22,1 \%$ \\
\hline $\begin{array}{l}\text { Usa medicamento colesterol } \\
\text { elevado }\end{array}$ & 12 & $9,8 \%$ & 14 & $10,1 \%$ & 26 & $9,9 \%$ \\
\hline \multicolumn{7}{|l|}{ Frequência de uso de área verde } \\
\hline mínimo 1 vez/semana & 63 & $51,2 \%$ & 60 & $43,2 \%$ & 123 & $46,9 \%$ \\
\hline \multicolumn{7}{|l|}{ Ter "área verde" em casa } \\
\hline jardim & 34 & $27,6 \%$ & 56 & $40,3 \%$ & 90 & $34,4 \%$ \\
\hline horta & 17 & $13,8 \%$ & 12 & $8,6 \%$ & 29 & $11,1 \%$ \\
\hline gramado & 12 & $9,8 \%$ & 12 & $8,6 \%$ & 24 & $9,2 \%$ \\
\hline pomar & 14 & $11,4 \%$ & 10 & $7,2 \%$ & 24 & $9,2 \%$ \\
\hline
\end{tabular}


A prevalência de fumantes foi de $19,1 \%$, taxa maior que a nacional de $14,8 \%$ (BRASIL, 2011). A maioria dos fumantes é do sexo masculino, no entanto a diferença não é significativa, coincidindo com a realidade nacional (BRASIL, 2011).

O uso de medicamento para hipertensão arterial revelou uma prevalência de 22,1\%, valor bastante próximo à taxa nacional, na qual se estima um valor de $22,7 \%$ da população adulta (BRASIL, 2011). Na amostra analisada não foi observada diferença significativa entre gêneros.

A questão ter área verde em casa se refere à residência possuir um espaço de solo permeável onde os moradores possam ter contato com a natureza. A Figura 1 apresenta, com relação a gênero, os meios de locomoção utilizados pela população. Nesta questão o entrevistado respondia qual o meio de locomoção mais utilizado no dia a dia, podendo relatar um ou mais.

Figura 1. Distribuição dos meios de locomoção no cotidiano segundo gênero Figure 1. Distribution of daily means of transportation according to gender

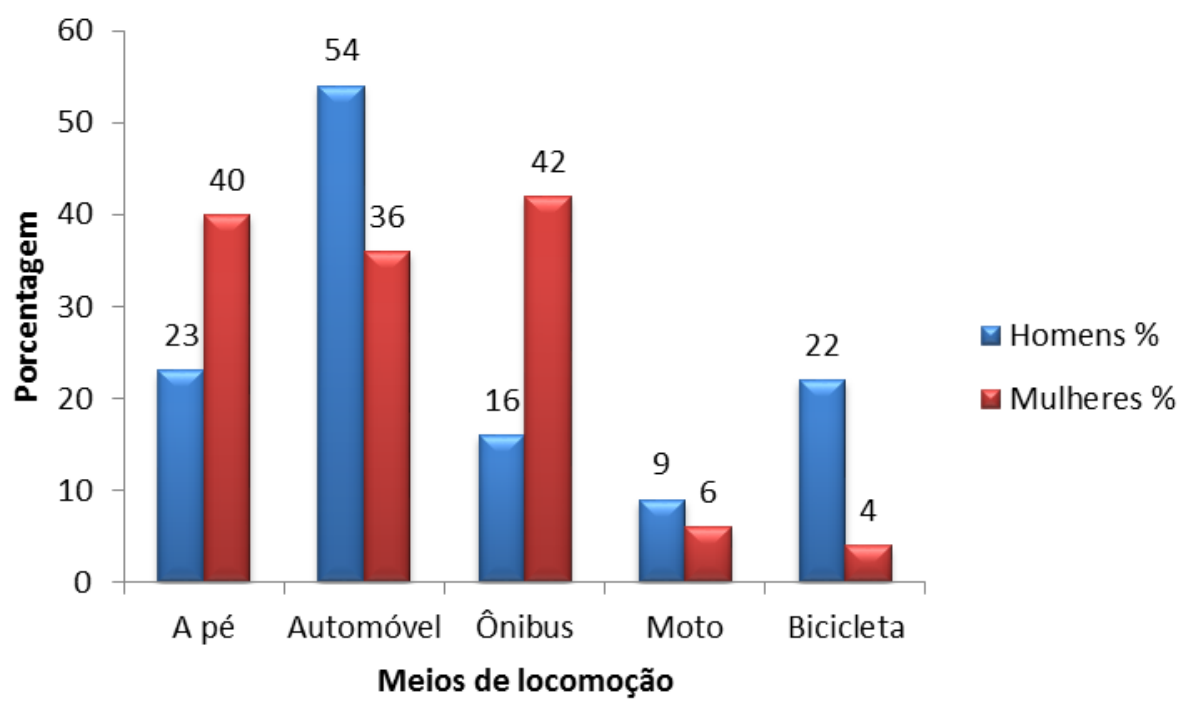

Comparando-se os meios de locomoção por gênero observam-se diferenças significativas $(p<0,05)$. As mulheres andam mais a pé e utilizam-se mais de ônibus no cotidiano. Por outro lado, os homens fazem mais uso de automóvel e de bicicleta. A pesquisa de Kessel et al. (2009), aponta que a falta de carro funciona como barreira, desmotivando o acesso à áreas verdes. O estudo de Jones et al. (2009) constata que pessoas com maior mobilidade, ou que possuam condução própria, frequentam mais áreas verdes em Bristol, Inglaterra. 
Dos entrevistados 39,7\% estavam com Índice de Massa Corporal (IMC) normal, 37\% estavam acima do peso, $21 \%$ demonstram ter obesidade e $2,3 \%$ se encontravam abaixo do peso. Não foi revelada diferença significativa entre os gêneros, no que se refere à classificação do IMC. A média nacional de obesidade é de $15 \%$, segundo levantamento realizado pelo Ministério da Saúde (BRASIL, 2010). Isto pode indicar que a obesidade em Mogi Mirim está acima da média nacional. Entretanto, seria necessária a realização de uma pesquisa mais específica sobre o tema, visando confirmar esta observação. O estudo de Nielsen e Hansem (2007) revela que na Dinamarca as características do bairro influenciam o nível de atividade física e por meio deste a probabilidade de obesidade.

\section{Atividades realizadas na área verde}

Do total da amostra, observou-se que $46,9 \%$ dos entrevistados frequentavam área verde no mínimo uma vez por semana. Na Tabela 2 é possível verificar as atividades realizadas na área verde segundo a distribuição por gênero, considerando o total da amostra.

Tabela 2. Distribuição das atividades realizadas nas áreas verdes segundo gênero Table 2. Distribution of activities in the green areas by gender

\begin{tabular}{lcccccc}
\hline \begin{tabular}{c} 
Atividade realizada na \\
\multicolumn{1}{c}{ área verde }
\end{tabular} & \multicolumn{2}{c}{ Homens } & \multicolumn{2}{c}{ Mulheres } & \multicolumn{2}{c}{ Total } \\
\hline Convívio social & 39 & $32 \%$ & 40 & $29 \%$ & 79 & $30 \%$ \\
Atividade Física & 38 & $31 \%$ & 39 & $28 \%$ & 77 & $29 \%$ \\
Lazer com criança & 28 & $23 \%$ & 29 & $21 \%$ & 57 & $22 \%$ \\
Passeio com cão & 15 & $12 \%$ & 9 & $6 \%$ & 24 & $9 \%$ \\
\hline
\end{tabular}

A atividade física é uma recomendação clara da Organização Mundial de Saúde e do Ministério da Saúde (BRASIL, 2010) que definem suficientes pelo menos 30 minutos diários de atividade física em cinco ou mais dias da semana, para uma vida saudável. Neste contexto, a área verde se reveste de importância como um elemento para promoção da saúde da população. Em Mogi Mirim, no estudo conduzido pela amostra, $29,4 \%$ da população frequentam esses espaços para realizar algum tipo de atividade física (AF). São necessários mais estudos para verificar a intensidade, a duração da prática e o tipo de AF feita pela população. De todo modo, é possível afirmar que, levando-se em conta apenas a atividade física realizada na área verde, o valor encontrado neste estudo é superior à 
nacional, onde apenas $14,9 \%$ da população adulta praticam atividade física suficiente no lazer (MALTA et al., 2009).

No estudo de Schipperijn et al. (2010), os autores avaliaram diferentes fatores que influenciam o uso de áreas verdes na Dinamarca e concluíram que ter um cão está associado à frequência de idas às áreas verdes. A influência desta variável pode ser explicada pela necessidade do cão em se exercitar, na disponibilidade de espaço oferecido pela área verde e na companhia e/ou segurança que o animal proporciona (MARQUES, 2013).

Considerando a questão acerca da área verde frequentada, os entrevistados poderiam citar mais de um local. Não havia sugestões de resposta por se tratar de uma questão aberta. A Figura 2 expõe a distribuição das áreas citadas.

Figura 2. Distribuição da frequência de áreas consideradas verdes pela população na cidade de Mogi Mirim

Figure 2. Frequency distribution of areas considered as green areas by the population in the city of Mogi Mirim

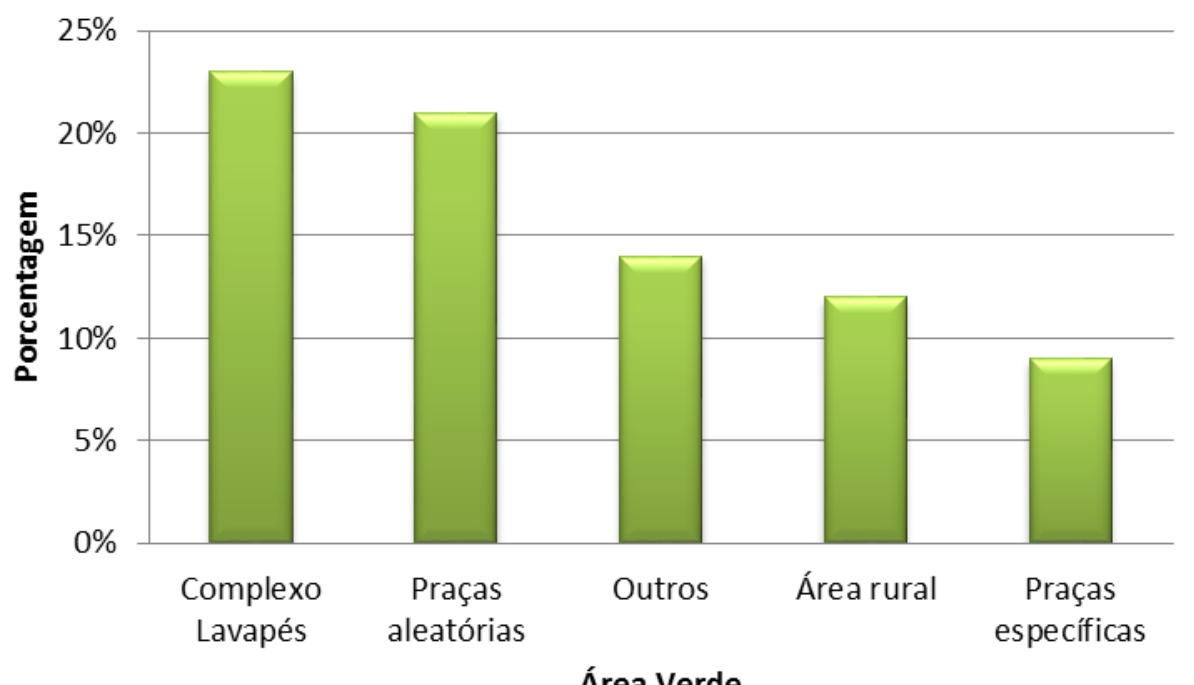

Área Verde

Segundo a Figura 2, dos entrevistados, 21\% afirmaram frequentar praças, sem preferência definida. A escolha é feita aleatoriamente conforme o caminho que estão percorrendo, denominadas como "praças aleatórias". Um total de 13 praças, especificadas pelo nome da praça ou do bairro, foi lembrado por $9 \%$ dos entrevistados. Em "outros", estão incluídas as opções; clubes, zoológico, horto, campo de futebol, e as respostas das pessoas que afirmaram frequentar área verde sem especificar qual. O Complexo Lavapés, área verde individualmente bem definida e delimitada, exposta na Figura 3, foi lembrada por $23 \%$ dos respondentes. 
Figura 3. Imagem de satélite do Complexo Lavapés

Figure 3. Satellite image of Complexo Lavapés

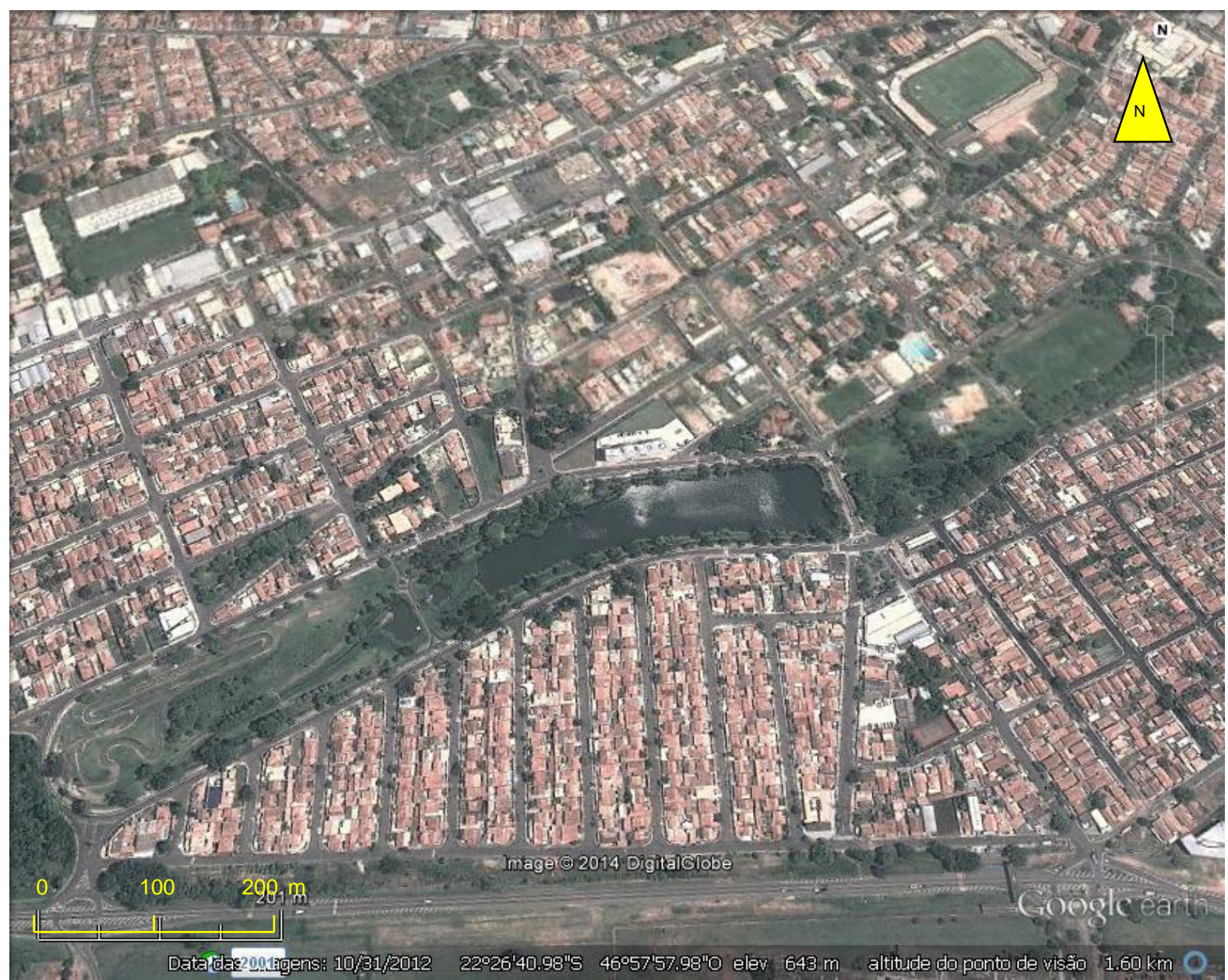

Fonte: GOOGLE EARTH (2012).

Por ser o Complexo Lavapés uma área verde específica foi possível calcular a distância da residência dos seus frequentadores, da amostra analisada. A Tabela 3 apresenta a distribuição dos frequentadores de acordo com a distância da área verde, a partir da coordenada de latitude $22^{\circ} 26^{\prime} 40^{\prime \prime}$ sul e longitude $46^{\circ} 57^{\prime} 50^{\prime \prime}$ oeste, representada pelo centro do lago, por intervalos de $500 \mathrm{~m}$. 
Tabela 3. Distribuição dos frequentadores do Complexo Lavapés segundo distância da moradia e tempo despendido de deslocamento a pé

Table 3. Distribution of users according to the distance from the residence to the Complexo Lavapés and walking travel time

\begin{tabular}{lccc}
\hline $\begin{array}{l}\text { Distância (m) da } \\
\text { residência ao Complexo } \\
\text { Lavapés }\end{array}$ & $\begin{array}{c}\text { Número de } \\
\text { entrevistados }\end{array}$ & $\begin{array}{c}\text { Tempo } \\
(\mathrm{min})^{*}\end{array}$ & $\%$ \\
\hline 0 a 500 & 6 & 6 & $10,0 \%$ \\
501 a 1000 & 12 & 6 a 12 & $20,0 \%$ \\
1001 a 1500 & 7 & 12 a 18 & $11,7 \%$ \\
1501 a 2000 & 9 & 18 a 24 & $15,0 \%$ \\
2001 a 2500 & 6 & 24 a 30 & $10,0 \%$ \\
2501 a 3000 & 14 & 30 a 36 & $23,3 \%$ \\
3001 a 3500 & 4 & 36 a 42 & $6,7 \%$ \\
3501 a 4000 & 1 & 42 a 48 & $1,7 \%$ \\
4001 a 4500 & 1 & 48 a 54 & $1,7 \%$ \\
Total & 60 & & 100 \\
\hline
\end{tabular}

* Velocidade estimada de $5 \mathrm{~km} \cdot \mathrm{h}^{-1}$

Dos frequentadores do Complexo Lavapés, 90\% residem a até três quilômetros de distância. Esse percurso pode ser feito em média gastando 33 minutos de caminhada. $A$ grande procura por essa área verde pode ser explicada pela estrutura oferecida, que conta com campo de futebol, quadras, teatro de arena, equipamentos para exercícios físicos, pistas para caminhada e ciclovia. Nielsen e Hansen (2007) mostram que o uso de áreas verdes diminui com o aumento da distância entre a residência, observamos que o limite desta distância em Mogi Mirim é de três quilômetros e que a partir disso a frequência de uso diminui.

A Figura 4 apresenta a distribuição dos frequentadores da área verde, Complexo Lavapés. 
Figura 4. Distribuição total dos frequentadores do Complexo Lavapés

Figure 4. Fully distribution of Complexo Lavapés users

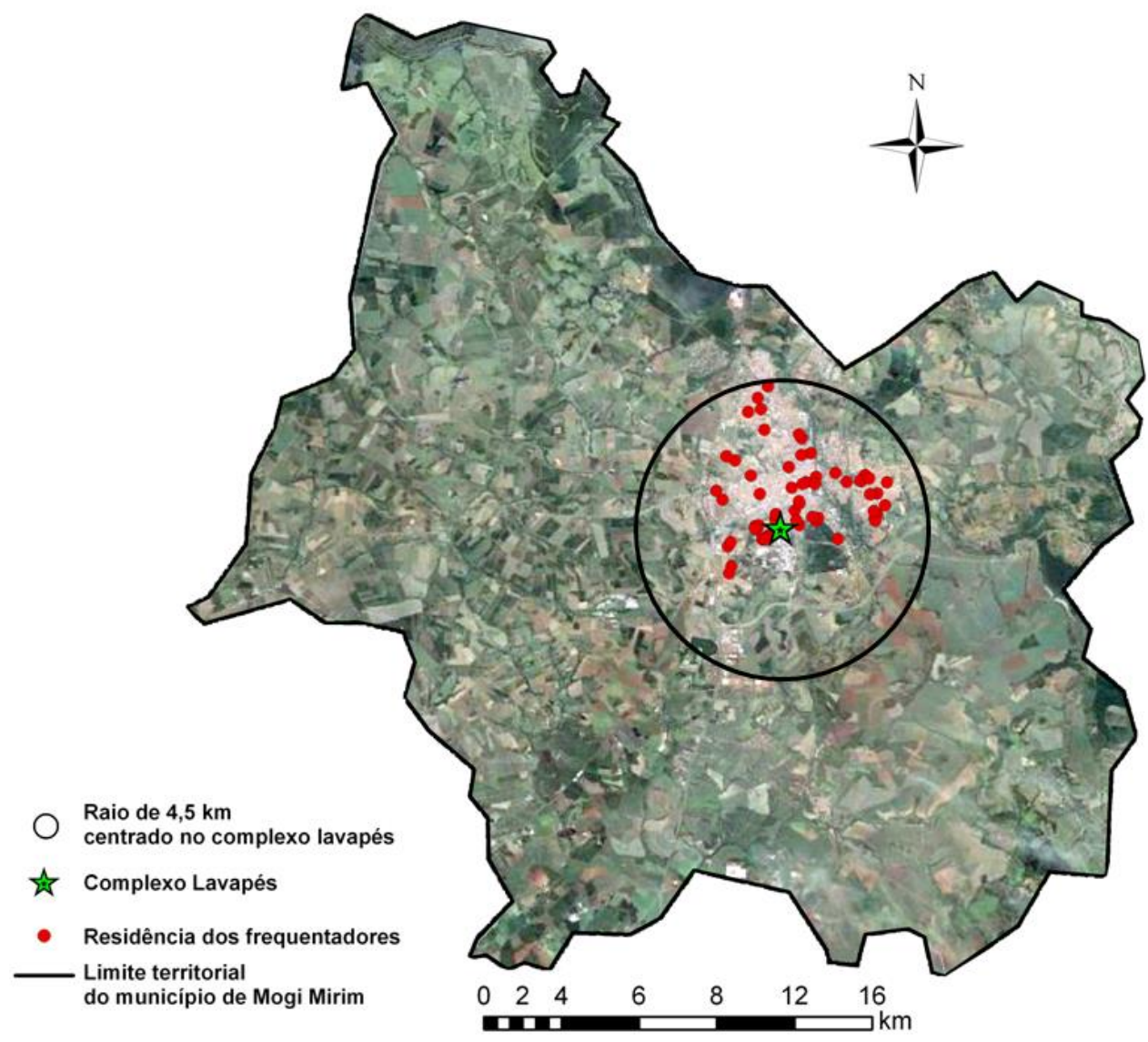

Apesar de o município de Mogi Mirim contar com 67 praças, a Figura 4 demonstra que os frequentadores do Complexo Lavapés estão distribuídos em um raio de 4,5 quilômetros, que engloba praticamente toda área urbana. Tal constatação salienta a preferência dada ao Complexo Lavapés pela população, em relação às praças.

Cabe lembrar que inúmeras pessoas caminham ou utilizam ônibus como principal meio de transporte, fator que dificulta o uso de áreas verdes distantes da residência. Assim as praças representam um grande potencial de aumento de uso de áreas verdes pela população.

\section{CONCLUSÃO}

Esta pesquisa identificou as áreas verdes frequentadas pela população da cidade de Mogi Mirim - SP. A área verde mais frequentada é também a mais estruturada, mesmo não 
sendo a mais próxima da residência. Há a necessidade em se pesquisar localmente (em cada bairro) sobre as causas de desmotivação do indivíduo a frequentar a área verde mais próxima de sua residência, uma vez que a cidade possui 67 praças. Observou-se que o acesso a áreas verdes envolve não somente a distância física, mas também a estrutura adequada à necessidade da população próxima e a segurança do local.

A metodologia de pesquisa para avaliação das características socioeconômicas da população, explorada neste estudo trata-se de um recurso relevante, que pode ser reproduzido com o fim de estimular a frequência de uso de áreas verdes, por auxiliar no planejamento de áreas mais adequadas ao perfil da população do seu entorno. Estudos com este enfoque vêm sendo realizados em diversos países, fornecendo subsídios para políticas públicas. Por fim, uma perspectiva de planejamento urbano, que considere as especificidades da população local e o efeito das áreas verdes no seu bem-estar, poderia ser uma estratégia de promoção da saúde e melhoria da qualidade de vida.

\section{REFERÊNCIAS}

BRASIL. Ministério da Saúde. Secretaria de Vigilância em Saúde. Secretaria de Gestão Estratégica e Participativa. Vigitel Brasil 2010: vigilância de fatores de risco e proteção para doenças crônicas por inquérito telefônico. Brasília: Ministério da Saúde, 2011.

BRASIL. Ministério da Saúde. Secretaria de Vigilância em Saúde. Vigitel Brasil 2011: vigilância de fatores de risco e proteção para doenças crônicas por inquérito telefônico. Brasília: Ministério da Saúde, 2012. 132p.:il. - (Série G. Estatística e Informação em Saúde). Disponível em: http://www.blog.saude.gov.br/obesidade-atinge-quase-metade-da-populacaobrasileira/ Acesso em: 16 de abril 2013.

GIL, A. C. Metodologia da pesquisa. São Paulo: Atlas, 1995.

GOOGLE EARTH. Google Inc. Disponível em: <http://www.earth.google.com>. Acesso em: 31 outubro 2012.

GRAHN, P.; STIGSDOTTER, U. Landscape planning and stress. Urban Forestry \& Urban Greening, v. 2, p.1-18, 2003.

IBGE - Instituto Brasileiro de Geografia e Estatística. Censo Demográfico 2010. Disponível em: < http://www.ibge.gov.br/cidadesat/topwindow.htm?1>. Acesso em: 23 agosto 2011. 
JONES, A.; HILLSDON,M.; COOMBES,E. Greenspace access, use, and physical activity: Understanding the effects of area deprivation. Preventive Medicine, v. 49, p. 500-505, 2009.

KELSEY, J.L.; THOMPSON, W.D.; EVANS, A.S. Methods in observational epidemiology. Oxford University Press, New York, 1986.

KESSEL, A.; GREEN, J.; PINDER, R.; WILKINSON, P.; GRUNDY, C.; LACHOWYCZ, K. Multidisciplinary research in public health: A case study of research on access to green space. Public health, v. 123, n. 1, p. 32-40, 2009.

MACHADO, F.H.; SILVA, L.F.; DUPAS, F.A.; MATTEDI, A. P.; VERGARA, F.E. Economic assessment of urban watersheds: developing mechanisms for environmental protection of the Feijão river, São Carlos - SP, Brazil. Brazilian Journal of Biology, v. 74, n. 3, p. 677684, 2014.

MALTA, D.C.; MOURA, E.C.; CASTRO, A.M.; ALENCAR CRUZ, D.K.; MORAIS NETO, O.L.; MONTEIRO, C.A. Padrão de atividade física em adultos brasileiros: resultados de um inquérito por entrevista telefônicas, 2006. Epidemiologia e Serviços de Saúde 2006; v.18, n.1 Brasília março 2009.

MARQUES, V.R.; Uso de áreas verdes em Mogi Mirim, SP: diagnósticos de alguns fatores associados. 2013. 81f. Dissertação (Mestrado em Meio Ambiente e Recursos Hídricos) - Universidade Federal de Itajubá, Itajubá, 2013.

MATIAS, L.F.; CAPORUSSO, D. Áreas verdes urbanas: avaliação conceitual e metodológica a partir do estudo de caso na cidade de Paulínia - São Paulo, Brasil. In: ENCONTRO DE GEÓGRAFOS DE AMÉRICA LATINA, 12, 2009, Montevideo, Uruguay. Anais... EGAL 2009. Disponível em: http://egal2009.easyplanners.info/erea05/5353_Matias_Lindon_Fonseca.pdf. Acesso em: março 2013.

NIELSEN, T.S.; HANSEN, K.B. Do green areas affect health? Results from a Danish survey on the use of green areas and health indicators. Health \& Place, v.13, p. 839-850. 2007.

RICHARDSON, R.J. Pesquisa social: métodos e técnicas. 3 ed. São Paulo, Atlas, 2008, p. 334.

SCHIPPERIJN, J.; STIGSDOTTER, U.K.; RANDRUP, T.B.; TROELSEN, J. Influences on the use of urban green space - A case study in Odense, Denmark. Urban Forestry \& Urban Greening, v.9, p. 25-32, 2010. 